Supporting Information for

\title{
Unconventional High-Index Facet of Iridium Boosts Oxygen Evolution Reaction: How the Facet Matters
}

Fei Xue ${ }^{\dagger,}, \|$ Xinyang Guo ${ }^{\dagger}, \|$, Boya Min ${ }^{\dagger}$, Yitao $\mathrm{Si}^{\dagger}$, Hongwen Huang ${ }^{\ddagger}$, Jinwen Shi ${ }^{\dagger}$, Maochang Liu ${ }^{*}$ *ศ

${ }^{\dagger}$ International Research Center for Renewable Energy \& State Key Laboratory of Multiphase Flow in Power Engineering, Xi'an Jiaotong University, Xi'an, Shaanxi 710049, P. R. China

${ }^{\ddagger}$ College of Materials Science and Engineering, Hunan University, Changsha, Hunan 410082, P. R. China

'Suzhou Academy of Xi’an Jiaotong University, Suzhou, Jiangsu 215123, P. R. China

"These two authors contribute equally to the manuscript.

*To whom correspondence should be addressed.Email: maochangliu@mail.xjtu.edu.cn; Phone: +86-(29)-82668296-18; Fax: +86-(29)-82669033. 


\section{Experimental Section}

\section{Chemicals and materials}

Sodium tetrachloropalladate $\left(\mathrm{Na}_{2} \mathrm{PdCl}_{4}, 98 \%\right)$, sodium hexachloroiridate hydrate $\left(\mathrm{Na}_{3} \mathrm{IrCl}_{6} \cdot \mathrm{xH}_{2} \mathrm{O}, 98 \%\right)$, poly(vinyl pyrrolidone) (PVP, $\left.\mathrm{MW} \approx 55,000\right)$ were all purchased from Sigma-Aldrich. Palladium tetrachloride acid $\left(\mathrm{H}_{2} \mathrm{PdCl}_{4}, 99 \%\right)$, ascorbic acid (AA, 99\%), hexadecyl trimethyl ammonium bromide (CTAB), formaldehyde solution ( $\mathrm{HCHO}, 35 \%)$, acetic acid (99.7\%), potassium bromide $(\mathrm{KBr}, 99 \%)$, ethylene glycol (EG, 99\%), perchloric acid $\left(\mathrm{HClO}_{4}, 70 \%\right)$ and absolute ethyl alcohol were obtained from Sinopharm Reagent Co. LTD. Commercial Ir/C catalyst was provided by the Rhawan Reagent. All reagents were analytical pure and used without further purification. The water used in experiments are de-ionized water with a resistivity of $18.2 \mathrm{M} \Omega \mathrm{cm}$.

\section{Preparation of seed of 45 nm Pd nanocubes}

The Pd nanocubes in edge length of $45 \mathrm{~nm}$ were synthesized according to a previously reported two-step protocol, involving a pre-synthesis of $22 \mathrm{~nm}$ Pd nanocubes and subsequent seed-mediated growth.

In a typical pre-synthesis of $22 \mathrm{~nm}$ Pd nanocubes, $0.5 \mathrm{~mL} \mathrm{H}_{2} \mathrm{PdCl}_{4}$ solution (10 $\mathrm{mM})$ and $10 \mathrm{~mL}$ CTAB solution $(12.5 \mathrm{mM})$ were well-mixed in a $25 \mathrm{~mL}$ vial and preheated at $95{ }^{\circ} \mathrm{C}$ for 5 min under magnetic stirring. Then $80 \mu \mathrm{L}$ fresh AA solution $(100 \mathrm{mM})$ was introduced into the mixed solution. Afterward, the reaction was allowed to maintained at $95{ }^{\circ} \mathrm{C}$ for another $30 \mathrm{~min}$. After being washed with DI water for three times via centrifugation, the $22 \mathrm{~nm} \mathrm{Pd}$ nanocubes were redispersed in $10.58 \mathrm{~mL}$ of DI water.

Then seed-mediated growth was employed to synthesize $45 \mathrm{~nm}$ Pd nanocubes, with $22 \mathrm{~nm}$ Pd nanocubes as seeds. Briefly, $200 \mu \mathrm{L}$ suspension of $22 \mathrm{~nm}$ Pd nanocubes, $125 \mu \mathrm{L} \mathrm{H}_{2} \mathrm{PdCl}_{4}$ solution $(10 \mathrm{mM}), 5 \mathrm{~mL} \mathrm{CTAB}$ solution $(50 \mathrm{mM}), 25 \mu \mathrm{L}$ AA solution $(100 \mathrm{mM})$ were hosted in another $25 \mathrm{~mL}$ vial at ambient temperature. After being magnetically stirred for $10 \mathrm{~min}$ to ensure complete dissolution, the mixture was then 
subjected to heating in oil bath at $40{ }^{\circ} \mathrm{C}$ for $14 \mathrm{~h}$. Finally, the product was collected by centrifugation, washed with DI water for three times, and then re-dispersed in $5 \mathrm{~mL}$ $\mathrm{H}_{2} \mathrm{O}$ for further use.

\section{Preparation of seed of $50 \mathbf{~ n m ~ P d ~ n a n o c t a h e d r o n ~}$}

The $50 \mathrm{~nm}$ Pd nanoctahedron was prepared by two successive seed-mediated growth. The process initiated from formation of $31 \mathrm{~nm}$ nanoctahedron induced by 16 $\mathrm{nm}$ cubic seed, followed by construction of $50 \mathrm{~nm}$ Pd nanoctahedron mediated from the $31 \mathrm{~nm}$ octahedral seed.

In a typical synthesis, the $16 \mathrm{~nm}$ nanocubes were preferentially prepared. ${ }^{2}$ Specifically, $8 \mathrm{~mL}$ of aqueous solution, containing PVP (105 mg), KBr (600 mg) and AA (60 mg), was placed in a $25 \mathrm{~mL}$ vial and heated to $80^{\circ} \mathrm{C}$ in an oil bath for $10 \mathrm{~min}$ under magnetic stirring. Then $3 \mathrm{~mL} \mathrm{Na}_{2} \mathrm{PdCl}_{4}$ aqueous solution $\left(19 \mathrm{mg} \mathrm{mL}^{-1}\right)$ was injected with a pipette in one shot. The final mixture was then kept at $80^{\circ} \mathrm{C}$ for extra 3

h. The $16 \mathrm{~nm}$ Pd nanocubes were collected by centrifugation and dispersed in $11 \mathrm{~mL}$ water.

After that, the above-prepared $16 \mathrm{~nm}$ nanocube suspension $(0.3 \mathrm{~mL}), \mathrm{PVP}(105$ $\mathrm{mg})$ and $\mathrm{HCHO}(0.1 \mathrm{~mL})$ were dissolved into $8 \mathrm{~mL}$ water in another $25 \mathrm{~mL}$ vial. After being preheated at $60{ }^{\circ} \mathrm{C}$ under magnetic stirring for $5 \mathrm{~min}, 3 \mathrm{~mL} \mathrm{Na} 2 \mathrm{PdCl}_{4}$ solution $(32 \mathrm{mM})$ was added into aforesaid solution, which retained at $60{ }^{\circ} \mathrm{C}$ for additional $3 \mathrm{~h}$. The products were then washed with water for three times via centrifugation, followed by redispersed in $11 \mathrm{~mL}$ water. At this point, the $31 \mathrm{~nm}$ Pd octahedral suspension can be acquired.

Subsequently, the $50 \mathrm{~nm}$ nanooctahedron was then obtained based on the $31 \mathrm{~nm}$ octahedral seed. Similarly, $8 \mathrm{~mL}$ water, $105 \mathrm{mg}$ PVP, $150 \mathrm{mg} \mathrm{KBr}, 10 \mathrm{mg}$ AA and 0.3 $\mathrm{mL}$ seed suspension of $31 \mathrm{~nm} \mathrm{Pd}$ octahedron were all placed in a $25 \mathrm{~mL}$ vial and then heated at $60{ }^{\circ} \mathrm{C}$ in an oil bath under magnetic stirring for $10 \mathrm{~min}$. After that, $3 \mathrm{~mL}$ $\mathrm{Na}_{2} \mathrm{PdCl}_{4}$ aqueous solution $(16 \mathrm{mM})$ was injected in one shot into the pre-heated solution. Then reaction was continued with heating at $60^{\circ} \mathrm{C}$ for $6 \mathrm{~h}$. The $50 \mathrm{~nm}$ octahedron seeds were then gathered via centrifugation, washed thrice with DI water 
and finally redispersed in $5 \mathrm{~mL} \mathrm{H}_{2} \mathrm{O}$ for later use.

\section{Preparation of seed of $49 \mathrm{~nm}-\mathrm{Pd}$ nanotrioctahedron}

The synthesis method for $49 \mathrm{~nm}$ Pd nanotrioctahedron is basically the same as that for $50 \mathrm{~nm}$ Pd nanoctahedron. The only difference is that the AA amount was increased from $10 \mathrm{mg}$ to $60 \mathrm{mg}$ in last step $(31 \mathrm{~nm}$ Pd octahedral seed-mediated conformation of $49 \mathrm{~nm}-\mathrm{Pd}$ nanotrioctahedron), while all other conditions remained unchanged.

\section{Preparation of Pd@Ir cubes (Pd@Ir cube)}

The Pd@ Ir cubes were synthesized through seed-mediated growth. ${ }^{3}$ In a standard synthesis, $0.6 \mathrm{mg} 45 \mathrm{~nm}$ Pd cubic seeds was mixed with $100 \mathrm{mg}$ PVP, $80 \mathrm{mg} \mathrm{KBr}, 20$ mg AA, and $3 \mathrm{~mL}$ EG in a $25 \mathrm{~mL}$ vial. The mixed solution was then held at $110{ }^{\circ} \mathrm{C}$ in an oil bath under magnetic stirring for $20 \mathrm{~min}$. Afterward, the reaction temperature was ramped to $180{ }^{\circ} \mathrm{C}$ in $10 \mathrm{~min}$. Subsequently, $2 \mathrm{~mL}$ of a $\mathrm{Na}_{3} \mathrm{IrCl}_{6}$ solution $\left(0.1 \mathrm{mg} \mathrm{mL}^{-1}\right.$, in EG) was dropwise added into the vial at a rate of $0.5 \mathrm{~mL} \mathrm{~h}^{-1}$ using a syringe pump. After the complete injection of $\mathrm{Na}_{3} \mathrm{IrCl}_{6}$ solution, the synthesis was proceed for an additional $1 \mathrm{~h}$ at $180{ }^{\circ} \mathrm{C}$. The solid product was collected by centrifugation, washed once with acetone and twice with DI water, and finally redispersed in $3 \mathrm{~mL}$ of DI water for further application.

\section{Preparation of Pd@Ir octahedron (Pd@Ir oct)}

The preparation method for Pd@Ir cubes is completely applicable to synthesis Pd@Ir octahedron, merely the $45 \mathrm{~nm}$ Pd cubic seeds are substituted by $50 \mathrm{~nm} \mathrm{Pd}$ octahedron.

\section{Preparation of Pd@Ir trioctahedron (Pd@Ir TOH)}

In a standard protocol, $0.6 \mathrm{mg} 49 \mathrm{~nm}$ Pd nanotrioctahedron, $100 \mathrm{mg}$ PVP and 20 mg of AA were all dissolved in $3.0 \mathrm{~mL}$ EG in a $25 \mathrm{~mL}$ vial and pre-heated at $100{ }^{\circ} \mathrm{C}$ for $20 \mathrm{~min}$. The reaction temperature was then fast raised to $130{ }^{\circ} \mathrm{C}$ within $10 \mathrm{~min}$. Subsequently, $2 \mathrm{~mL} \mathrm{Na} 3 \mathrm{IrCl}_{6}$ solution $\left(0.1 \mathrm{mg} \mathrm{mL}^{-1}\right)$ dissolved in $\mathrm{EG}$ was pumped into the reaction solution with a rate of $0.5 \mathrm{~mL} \mathrm{~h}^{-1}$. When the injection was finished, the 
reaction mixture was then remained at $130{ }^{\circ} \mathrm{C}$ for additional 1 h. The $\operatorname{Pd@Ir~}$ nanotrioctahedron product was collected by centrifugation, washed once with acetone and twice with water, and redispersed in $3 \mathrm{~mL}$ water.

\section{Instrumentation}

The X-ray diffraction (XRD) patterns were obtained from a PANalytical X'pert MPD Pro diffractometer equipped with Ni-filtered $\mathrm{Cu} \mathrm{K}_{\alpha}$ irradiation (wavelength = $1.5406 \AA, 40 \mathrm{kV} / 40 \mathrm{~mA})$. The morphologies and microstructures of the as-prepared samples were detected by FEI Tecnai G2 F30 S-Twin transmission electron microscope (TEM) attached with OXFORD MAX-80 energy-dispersive X-ray (EDX) detector at $300 \mathrm{kV}$. X-ray photoelectron spectroscopy (XPS) was acquired on a Kratos spectrometer (AXIS Ultra DLD) with monochromatic Al $\mathrm{K}_{\alpha}$ micro-fused monochromatized source $(h v=1486.6 \mathrm{eV})$ operating at a vacuum more than $10^{-7} \mathrm{P}$. The C 1s peak at $284.8 \mathrm{eV}$ of surface adventitious carbon was used for calibration. The quantitative determination over metal contents of the samples was accomplished via inductively coupled plasma mass spectrometry (ICP-MS) (NexION 350D, PerkinElmer). Each sample for ICP-MS measurements was prepared by dissolving the nanoparticles in aqua regia and then diluted to $100 \mathrm{ppb}$ level with $1 \%$ aqueous $\mathrm{HNO}_{3}$.

\section{Preparation of the Working Electrode}

In a typical procedure, the $\operatorname{Pd@Ir~core-shell~nanostructures~}(2 \mathrm{mg})$ and carbon support (Vulcan XC-72, $3 \mathrm{mg}$ ) were uniformly dispersed in 2 and $3 \mathrm{~mL}$ water, respectively. After being mixed in a $25 \mathrm{~mL}$ vial under continuous ultrasonication for 3 h, the carbon-supported Pd@Ir nanostructures (denoted as Pd@Ir/C) were collected by centrifugation, together with the commercial $\mathrm{Ir} / \mathrm{C}$ catalyst, treated in acetic acid $(10 \mathrm{~mL})$ at $60{ }^{\circ} \mathrm{C}$ for $3 \mathrm{~h}$ to clean the surfaces and subsequently washed with water and/or ethanol for 5 times. Once dried in an oven, each individual electrocatalyst and 5\% Nafion (40 $\mu \mathrm{L})$ were evenly suspended in water/isopropanol mixture solution $(1 \mathrm{~mL}$, volume ratio: 1/1) under ultrasonication for $30 \mathrm{~min}$ to form the homogeneous slurry. Hereafter, 57.4, 
47.2, 64.9 and 16.5 $\mu \mathrm{L}$ of suspensions for Pd@Ir cube/C, Pd@Ir oct/C, Pd@Ir TOH/C and commercial Ir/C catalyst (fixing the Ir loading amount at $1.2 \mu \mathrm{g}$ on RDE for all samples, determined by ICP-MS) were drop-casted onto a precleaned glassy carbon rotating disk electrode (RDE) with a geometric area of $0.13 \mathrm{~cm}^{2}$ and then dried at ambient conditions, resulting in the Ir loading of $9.5 \mu \mathrm{g}_{\mathrm{Ir}} \mathrm{cm}^{-2}$. After natural drying under ambient temperature, the working electrodes will be obtained.

\section{Electrochemical Measurements}

The electrochemical measurements were conducted with a CHI760D electrochemical workstation (Chenhua Instruments Co., Shanghai) in a conventional three-electrode system, with glassy carbon $\mathrm{RDEs}, \mathrm{Ag} / \mathrm{AgCl}$ (in saturated $\mathrm{KCl}$ ), Pt wire and $\mathrm{HClO}_{4}(0.1 \mathrm{M})$ as working electrode, reference electrode, counter electrode and electrolyte, respectively. All potentials were calibrated to the reversible hydrogen electrode (RHE).

The linear sweep voltammetry (LSV) curves of all the catalysts were detected at room temperature in an $\mathrm{O}_{2}$-saturated $\mathrm{HClO}_{4}$ solution $(0.1 \mathrm{M})$ in the potential region of 1.2-1.6 $\mathrm{V}$ at a scanning rate of $10 \mathrm{mV} \cdot \mathrm{s}^{-1}$ with electrode rotation $(1600 \mathrm{rpm})$ under $95 \%$ Ohmic iR-compensation. Before the LSV test, each electrocatalyst was swept for 10 cycles via CVs in the same potential range with a rate of $100 \mathrm{mV} \mathrm{s}^{-1}$ in an $\mathrm{O}_{2}$-saturated $\mathrm{HClO}_{4}$ solution $(0.1 \mathrm{M})$ at room temperature for activation. The TOF values for various samples were evaluated at overpotential of $300 \mathrm{mV}(1.53 \mathrm{~V}$ vs RHE) according to the following Equation S1.

$$
\mathrm{TOF}=\mathrm{j} \times \mathrm{A} /(4 \times \mathrm{F} \times \mathrm{n})
$$

Here, $\mathrm{j}$ is current density at a given potential, A denotes the surface area of RDE electrode, number 4 means 4 electrons per mole for producing 1 mole of $\mathrm{O}_{2}, \mathrm{~F}$ represents the Faraday constant $\left(96485.3 \mathrm{C} \mathrm{mol}^{-1}\right)$, and $\mathrm{n}$ is mole numbers of $\mathrm{Ir}$ on electrode. All the surficial Ir atoms were assumed to be utilized for catalyzing OER.

The accelerated durability tests were carried out through CV methods between 1.2 and $1.6 \mathrm{~V}$ for 1,000 cycles at a rate of $0.1 \mathrm{~V} \cdot \mathrm{s}^{-1}$ in an $\mathrm{O}_{2}$-saturated $\mathrm{HClO}_{4}$ solution $(0.1$ M) at room temperature. LSV curves were recorded again after sweeping 1,000 cycles 
in the same test condition for assessing the initial OER polarization curve.

Chronopotentiometry measurement for OER was conducted in $\mathrm{O}_{2}$-saturated $\mathrm{HClO}_{4}(0.1 \mathrm{M})$ solution for each electrocatalyst at a constant current density of $10 \mathrm{~mA}$ $\mathrm{cm}^{-2}$ with at a constant rotation rate of $1600 \mathrm{rpm}$ to remove the produced bubbles for a desirable time.

\section{Computational Methods and Methodologies}

Spin-polarized density functional theory (DFT) calculations are applied to simulate the oxygen evolution reaction (OER) on $\operatorname{Ir}(100)$, Ir (111) and $\operatorname{Ir}(331)$ facets, based on the Vienna Ab initio Simulation Package (VASP5.4.4). ${ }^{4,5}$ The valence electrons are described by the Kohn-Sham wave functions which is expanded by the plane wave basis, while the core electrons are described within the Projector Augmented-Wave (PAW) method. We chose generalized gradient approximation (GGA) with Perdew-Burke-Ernzerhof functional (GGA-PBE) that corrected by DFT-D2 to calculate the exchange-correlation interaction, ${ }^{6}$ due to this scheme has been validated in good performance on Gibbs free energy calculations for Iridium-mediated chemistry. ${ }^{7}$ The energy cutoff is set to $400 \mathrm{eV}$ and the Brillouin zone is sampled with a $(3 \times 3 \times 1)$ Gamma-centered Monkhorst-Pack k-point mesh. ${ }^{8}$ The energy convergence criteria is set as $10^{-5} \mathrm{eV}$ and the structures are relaxed until the force between atoms decease to $0.02 \mathrm{eV} / \AA$. The calculated surfaces for $\operatorname{Ir}(100)$ and $\operatorname{Ir}(111)$ were modeled as slabs with 5 layers. While for Ir (331) surface, a 7-layers slab model is substituted due to the much shorter layer distance of this surface. A vacuum layer of at least $16 \AA$ is applied in z-direction. For each slab model, the topmost two layers were able to relax, while the bottom two layers were kept fixed in bulk positions.

Of important note, it has been demonstrated to be difficult in stabilizing the adsorption of $\mathrm{OOH}$ for a bare surface of strong-binding metal (e.g., Ni, Ir and Rh). ${ }^{9} \mathrm{In}$ other words, OER activity could be ill-evaluated merely on a bare model facet. Therefore, in our case, all DFT calculations were conducted under oxygen coverage of $75 \%$ on outermost 3 -fold sites for pristine Ir surfaces according to early researches. ${ }^{10}$ To evaluate the OER activities on different surfaces, the following four widely 
acknowledged OER steps in acid conditions, ${ }^{11}$ as shown in Equation S2-S5, are simulated.

$$
\begin{gathered}
2 \mathrm{H}_{2} \mathrm{O}+{ }^{*} \rightarrow \mathrm{OH}^{*}+\mathrm{H}_{2} \mathrm{O}+\mathrm{e}^{-}+\mathrm{H}^{+} \\
\mathrm{OH}^{*} \rightarrow \mathrm{O}^{*}+\mathrm{e}^{-}+\mathrm{H}^{+} \\
\mathrm{O}^{*}+\mathrm{H}_{2} \mathrm{O} \rightarrow \mathrm{OOH}^{*}+\mathrm{e}^{-}+\mathrm{H}^{+} \\
\mathrm{OOH}^{*} \rightarrow \mathrm{O}_{2}+\mathrm{e}^{-}+\mathrm{H}^{+}
\end{gathered}
$$

The Gibbs free energy changes of each step are calculated according to Equation S6-S9 in reversible hydrogen electrode (RHE) with standard conditions (e.g., $\mathrm{pH}=0$ and $\mathrm{T}=298 \mathrm{~K})$.

$$
\begin{gathered}
\Delta G_{1}=G_{H \mathrm{H}^{*}}-G_{*}-G_{H_{2} O}+\frac{1}{2} G_{H_{2}}+k_{B} T \ln a_{H^{+}}-e U \\
\Delta G_{2}=G_{O^{*}}-G_{H O^{*}}+\frac{1}{2} G_{H_{2}}+k_{B} T \ln a_{H^{+}}-e U \\
\Delta G_{3}=G_{\mathrm{HOO} *}-G_{O^{*}}-G_{H_{2} O}+\frac{1}{2} G_{H_{2}}+k_{B} T \ln a_{H^{+}}-e U \\
\Delta G_{4}=4.92+G_{*}-G_{\mathrm{HOO} *}+2 G_{H_{2} O}-\frac{3}{2} G_{H_{2}}+k_{B} T \ln a_{H^{+}}-e U
\end{gathered}
$$

Notably, no bias is applied to the reaction, thus the term " $\mathrm{k}_{\mathrm{B}} \mathrm{T} \ln a_{\mathrm{H}^{+}}-\mathrm{eU}$ " equals zero. In addition, the Gibbs free energy, $\mathrm{G}_{\mathrm{i}}\left(\mathrm{i}=*\right.$ (pure surface), $\mathrm{OH}^{*}, \mathrm{O}^{*}, \mathrm{OOH}^{*}, \mathrm{H}_{2} \mathrm{O}$, and $\mathrm{H}_{2}$ ), is corrected with zero-point energy ( $\left.\mathrm{ZPE}\right)$ and for adsorbates-on-surface models and adsorbates in a vacuum box, as well as with entropies for adsorbates. Specifically, Gibbs free energy change can be obtained by following Equation S10.

$$
\mathrm{G}_{\mathrm{i}}=\mathrm{E}_{\mathrm{i}}+\mathrm{ZPE}_{\mathrm{i}}-\mathrm{TS}_{\mathrm{i}}\left(\mathrm{i}=* \mathrm{OH}^{*}, \mathrm{O}^{*}, \mathrm{OOH}^{*}, \mathrm{H}_{2} \mathrm{O} \text {, and } \mathrm{H}_{2}\right)
$$

Here, $\mathrm{E}_{\mathrm{i}}$ is the total energy acquired from DFT calculation. $Z \mathrm{PE}_{\mathrm{i}}$ and $\mathrm{S}_{\mathrm{i}}$ were correction values of ZPE and entropy of frequencies at $298 \mathrm{~K}$, which are tabulated in Table S5.

The theoretical overpotential $\eta$ was calculated as Equation S11:

$$
\eta=\frac{\max \left\{\Delta G_{1}, \Delta G_{2}, \Delta G_{3}, \Delta G_{4}\right\}}{e}-1.23 \mathrm{~V}
$$




\section{Reference}

(1) Niu, W.; Li, Z. Y.; Shi, L.; Liu, X.; Li, H.; Han, S.; Chen, J.; Xu G. Seed-mediated growth of nearly monodisperse palladium nanocubes with controllable sizes. Cryst. Growth Des. 2008, 8(12), 4440-4444.

(2) Jin, M.; Liu, H.; Zhang, H.; Xie, Z.; Liu, J.; Xia, Y. Synthesis of Pd nanocrystals enclosed by $\{100\}$ facets and with sizes. Nano Res. 2011, 4, 83-91.

(3) Xia, X.; Figueroa-Cosme, L.; Tao, J.; Peng, H.-C.; Niu, G.; Zhu, Y.; Xia, Y. Facile synthesis of iridium nanocrystals with well-controlled facets using seed-mediated growth. J. Am. Chem. Soc. 2014, 136, 10878-10881.

(4) Kresse, G.; Furthmuller, J. Efficient iterative schemes for ab initio total-energy calculations using a plane-wave basis set. Phys. Rev. B 1996, 54(16), 11169-11186.

(5) Kresse, G.; Furthmüller, J. Efficiency of ab-initio total energy calculations for metals and semiconductors using a plane-wave basis set. Comp. Mater. Sci. 1996, 6(1), $15-50$.

(6) Grimme, S. Semiempirical GGA-type density functional constructed with a longrange dispersion correction. J. Comp. Chem. 2006, 27(15), 1787-99.

(7) Hopmann, K. H. How accurate is DFT for iridium-mediated chemistry? Organometallics 2016, 35(22), 3795-3807.

(8) Monkhorst, H. J.; Pack, J. D. Special points for Brillouin-zone integrations. Phys. Rev. B 1976, 13(12), 5188-5192.

(9) Wang, A.; Zhao, Z.; Hu, D.; Niu, J.; Zhang, M.; Yan, K.; Lu, G. Tuning the oxygen evolution reaction on a nickel-iron alloy: via active straining. Nanoscale 2019, 11, 426430.

(10) Guo, H.; Fang, Z.; Li, H.; Fernandez, D.; Henkelman, G.; Humphrey, S. M.; Yu, G. Rational design of rhodium-iridium alloy nanoparticles as highly active catalysts for acidic oxygen evolution. ACS Nano 2019, 13(11), 13225-13234.

(11) Man, I. C.; Su, H. Y.; Calle-Vallejo, F.; Hansen, H. A.; Martínez, J. I.; Inoglu, N. G.; Kitchin, J.; Jaramillo, T. F.; Nørskov, J. K.; Rossmeisl, J. Universality in oxygen evolution electrocatalysis on oxide surfaces. ChemCatChem 2011, 3(7), 1159-1165. 

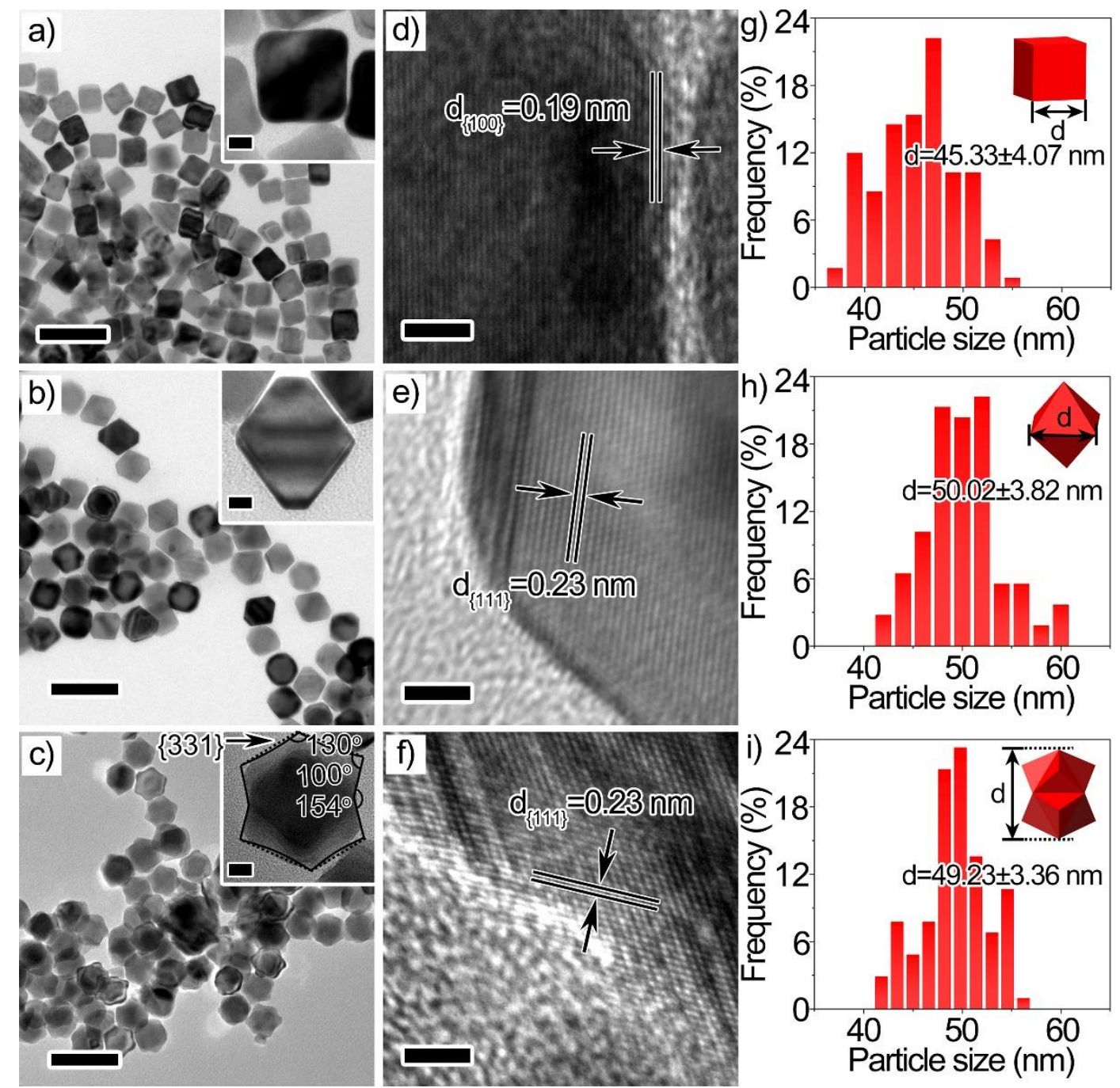

Fig. S1. (a-c) TEM images of as-prepared Pd nanocubes, Pd octahedron and Pd trioctahedron (scale bar: $100 \mathrm{~nm}$ ). The insets in these three figures show the typical individual nanoparticles in high magnification (scale bar: $10 \mathrm{~nm}$ ). (d-f) HRTEM images of Pd nanocubes, Pd octahedron and Pd trioctahedron (scale bar: $2 \mathrm{~nm}$ ). (g-i) The histograms of size distribution for Pd nanocubes, Pd octahedron and Pd trioctahedron. 

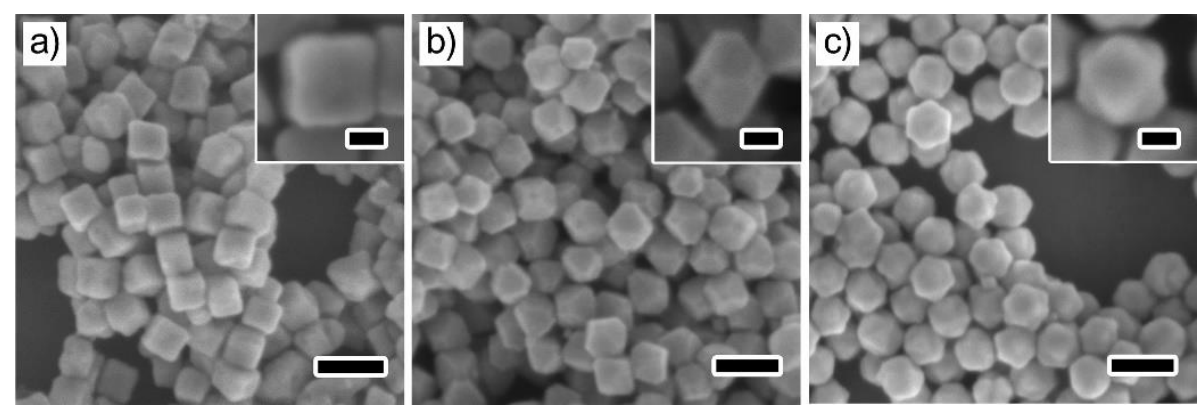

Fig. S2. SEM images of (a) Pd nanocube, (b) Pd nanoctahedron and (c) Pd nanotrioctahedron (scale bar: $100 \mathrm{~nm}$ ). The insets in these three figures are the typical individual nanoparticles in high magnification (scale bar: $20 \mathrm{~nm}$ ). 


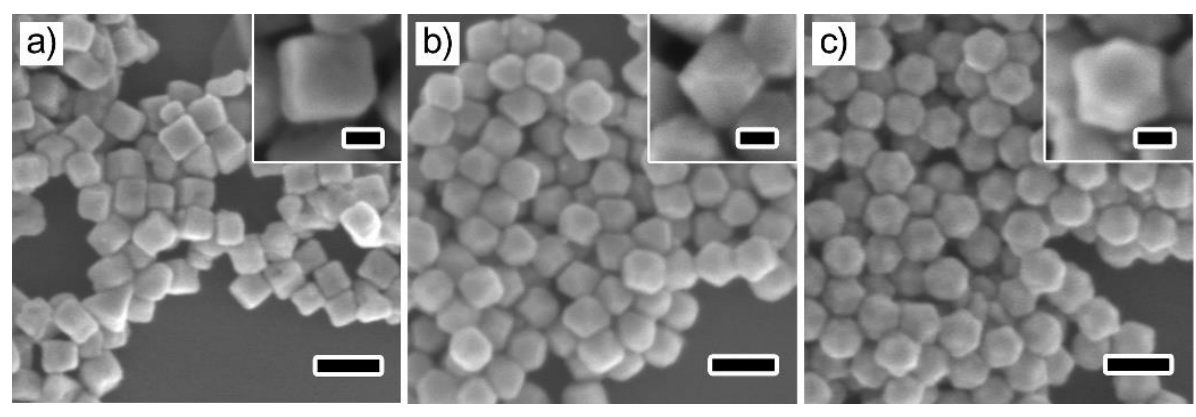

Fig. S3. SEM images of (a) Pd@Ir cube, (b) Pd@Ir oct and (c) Pd@Ir TOH (scale bar: 100 nm). The insets in these three figures are the typical individual nanoparticles in high magnification (scale bar: $20 \mathrm{~nm})$. 

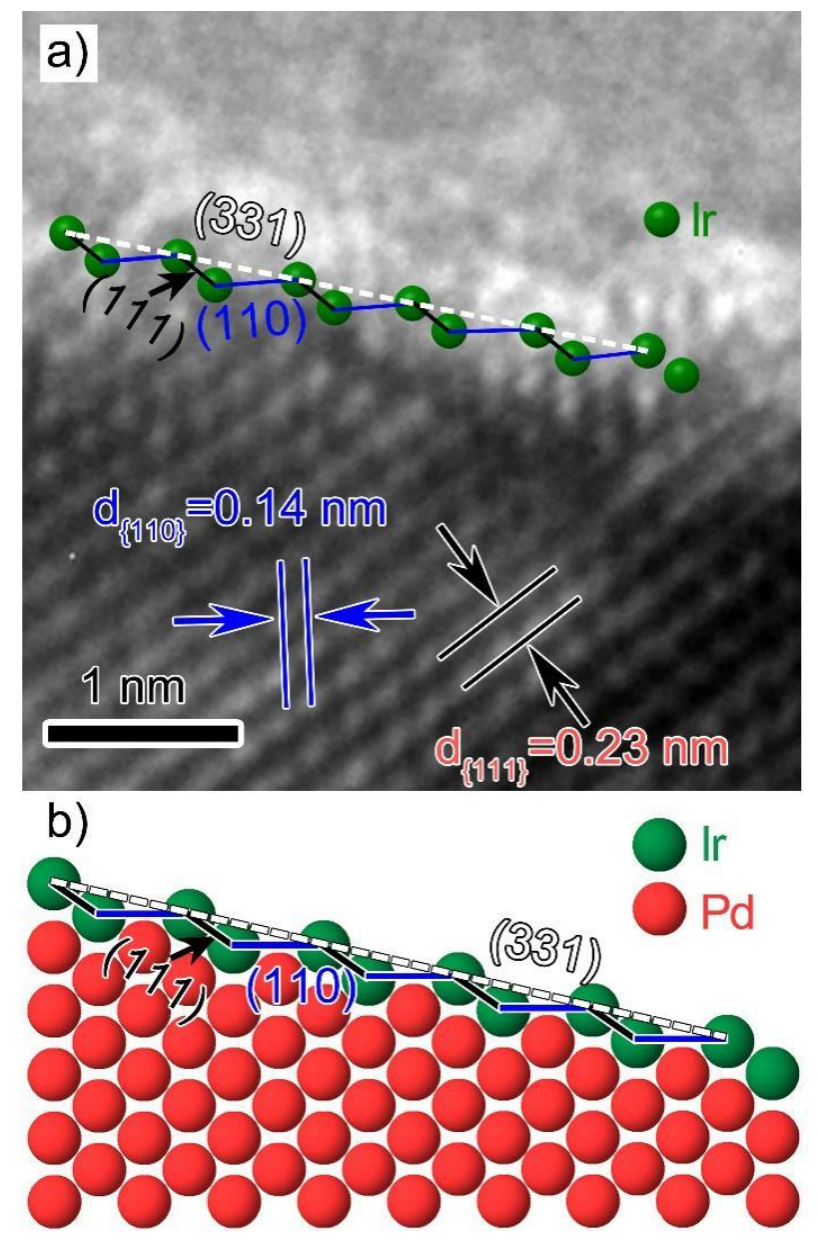

Fig. S4. (a) HRTEM image taken from the edge region of Pd@Ir TOH marked by the blue dashed box in Fig. 1g. (b) Atomic arrangement model of the surface Ir $\{331\}$ facet of Pd@Ir TOH. Keynote: green balls $=\mathrm{Ir}$ atoms; red balls $=\mathrm{Pd}$ atoms. 

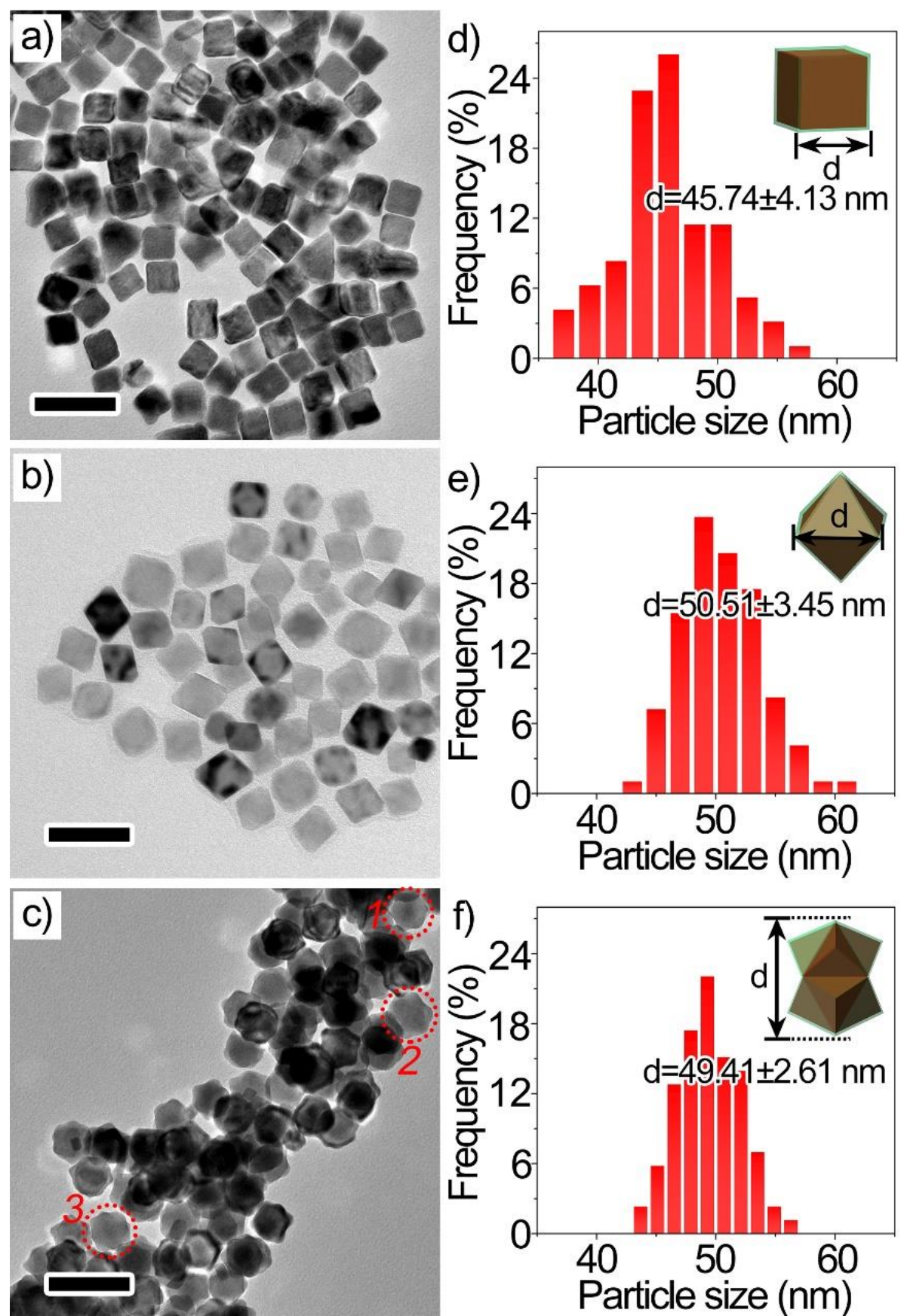

Fig. S5. (a-c) TEM images of Pd@Ir cube, Pd@Ir oct and Pd@Ir TOH (scale bar: 100 nm). (d-f) The corresponding histograms of size distribution for Pd@Ir cube, Pd@Ir oct and Pd@Ir TOH. The red dotted circles and mark numbers show representative Pd@Ir TOH nanoparticles projected along $<111>,<110>$, and $<100>$ directions, respectively. 


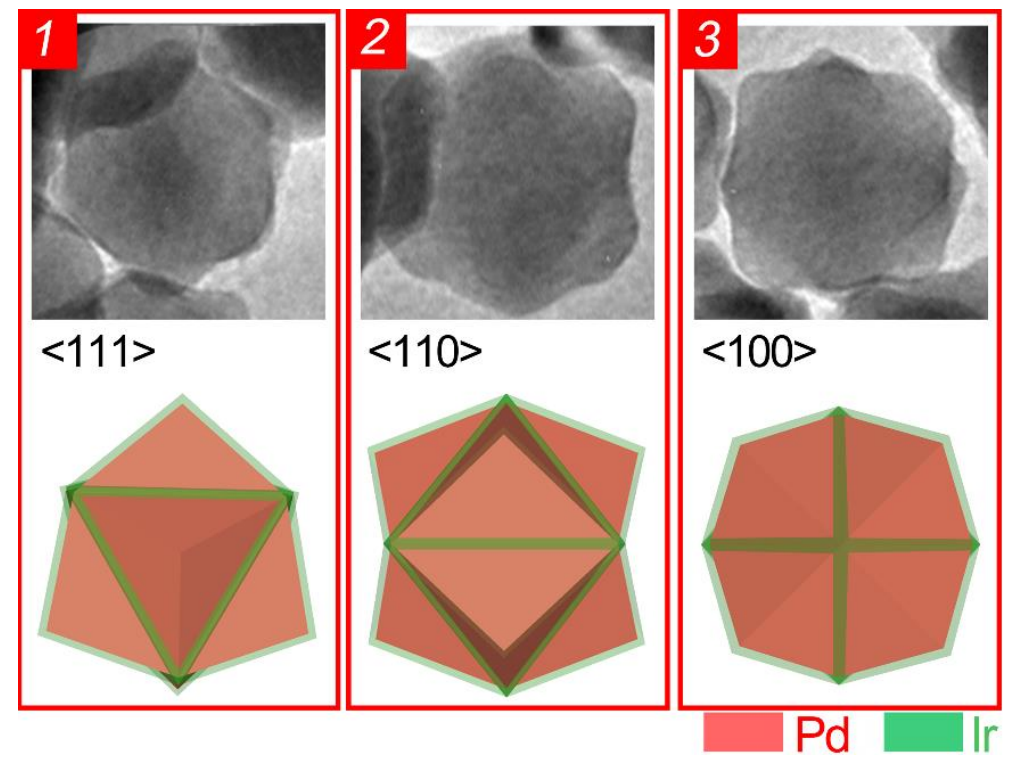

Fig. S6. The magnifying TEM images (top line) of three representative Pd@Ir TOH nanoparticles projected along $<111>,<110\rangle$, and $<100>$ directions highlighted in Fig. S5c in red dotted circles, respectively, together with the corresponding geometric models (bottom line). 

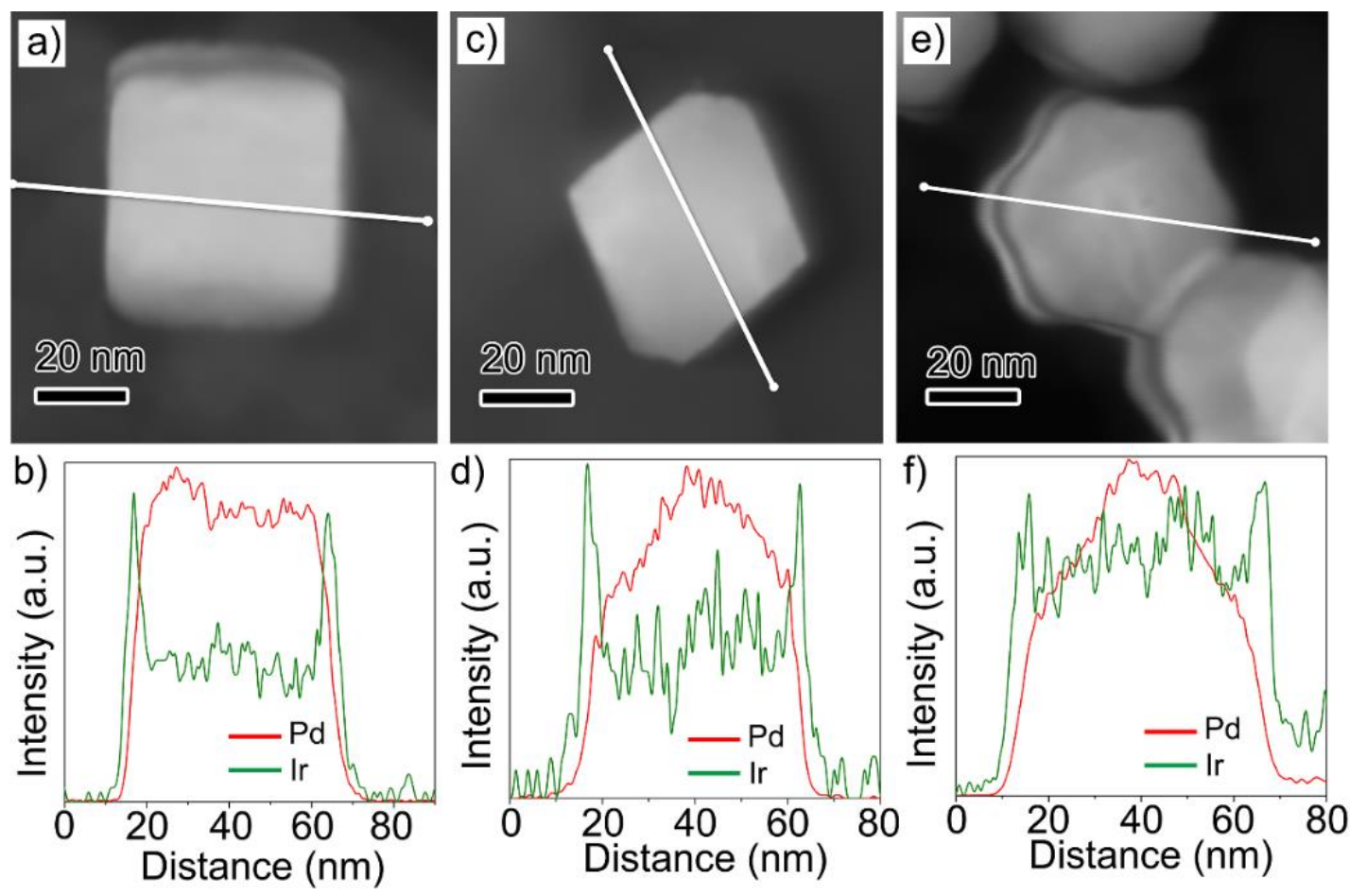

Fig. S7. (a), (c) and (e) STEM images of Pd@Ir cube, Pd@Ir oct and Pd@Ir TOH. (b), (d) and (f) corresponding TEM-EDX line scan analyses of the (b) Pd@Ir cube, (d) Pd@Ir oct and (f) Pd@Ir TOH along the white lines marked in (a), (c) and (e), respectively. 


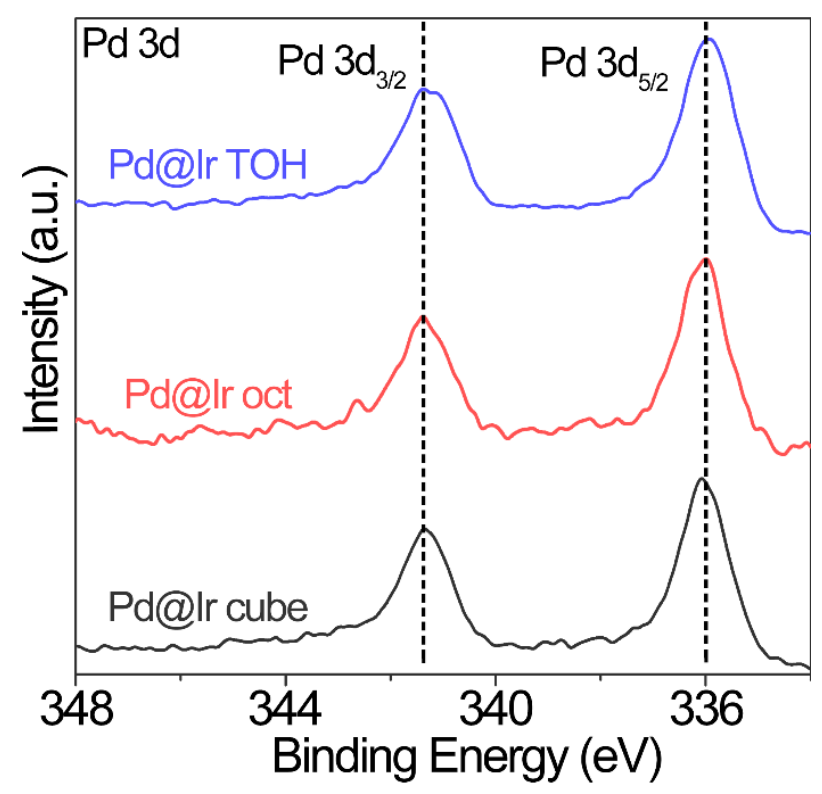

Fig. S8. Pd 3d high resolution XPS spectra in Pd@Ir cube, Pd@Ir oct and Pd@Ir TOH. 


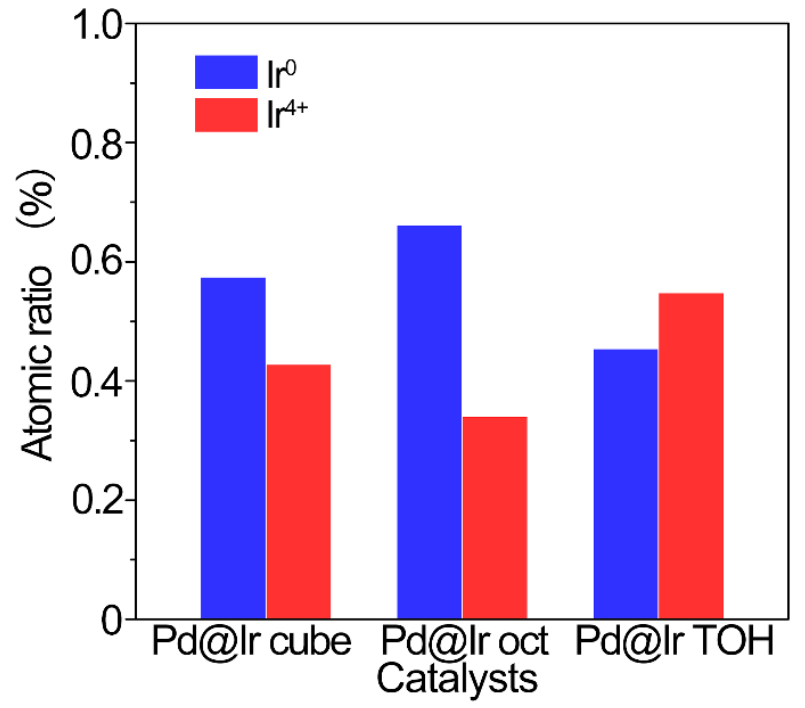

Fig. S9. Atomic ratios of $\operatorname{Ir}^{0}$ and $\mathrm{Ir}^{4+}$ in Ir shell for Pd@Ir core-shell electrocatalysts. 

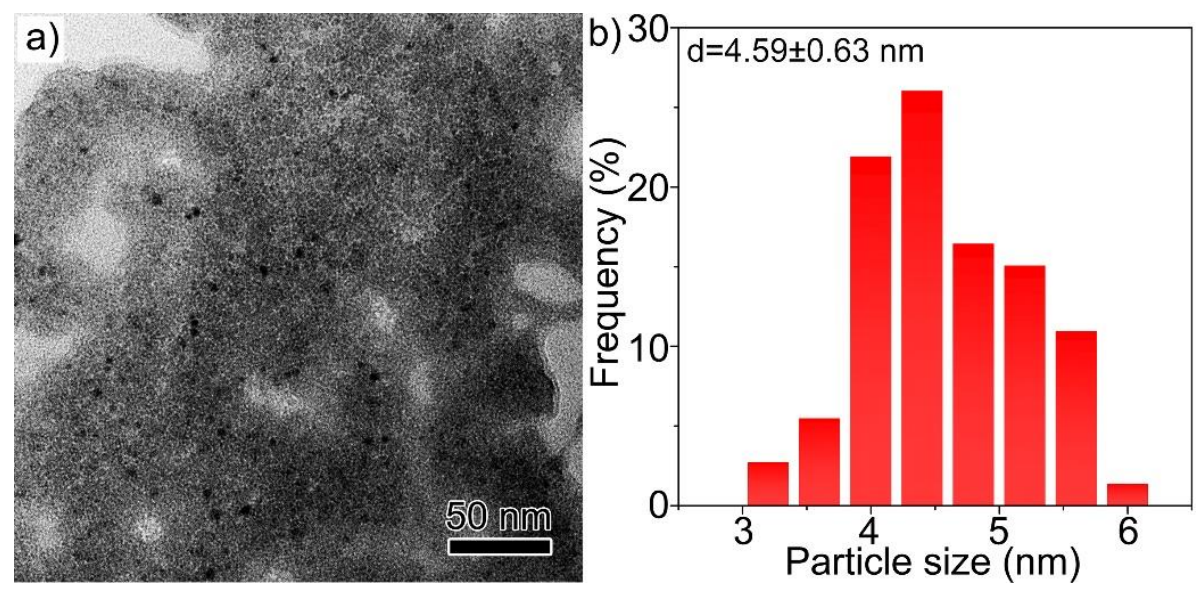

Fig. S10. (a) TEM image of commercial Ir/C. (b) The histograms of size distribution of Ir particles in commercial Ir/C. 


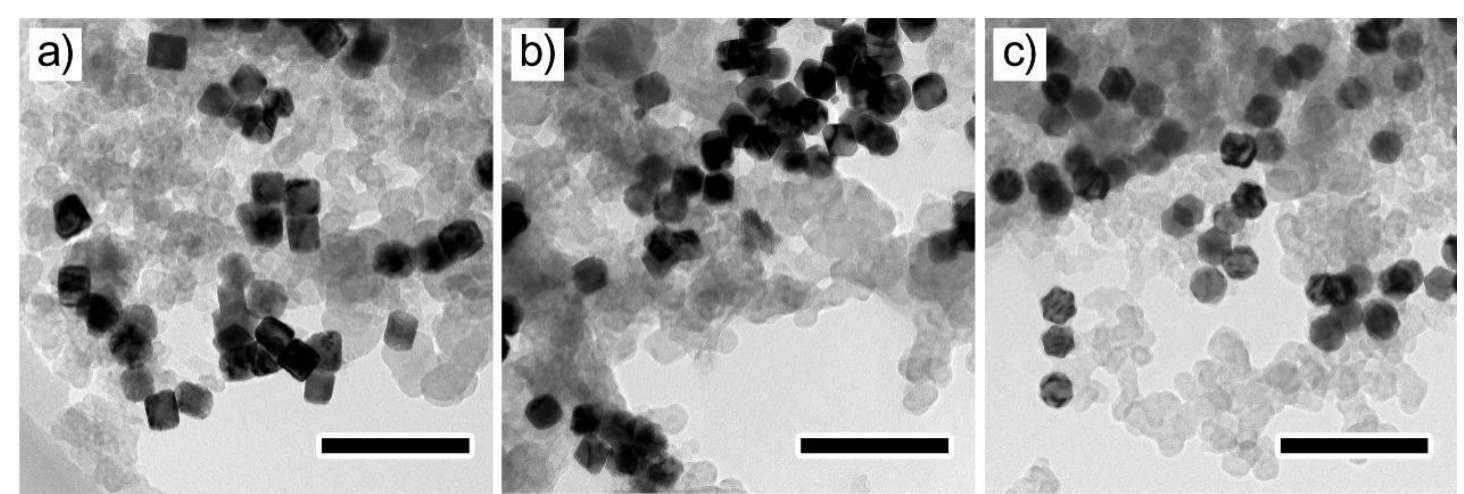

Fig. S11. TEM images of the as-prepared (a) Pd@Ir cube/C, (b) Pd@Ir oct/C and (c) Pd@Ir TOH/C (scale bar: $200 \mathrm{~nm}$ ). 

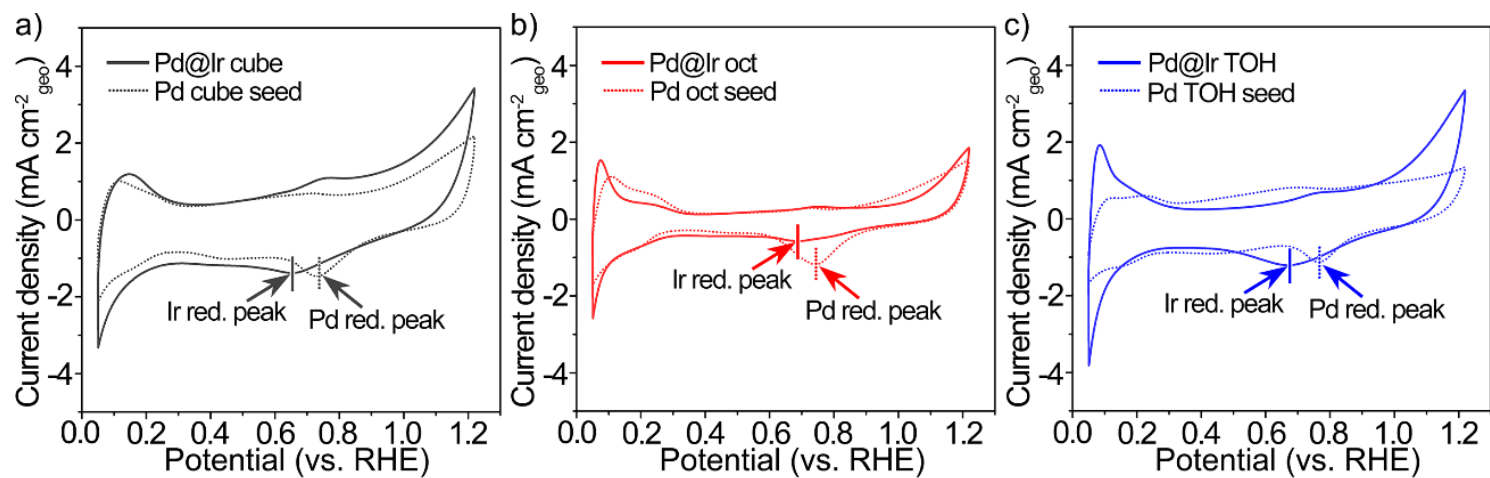

Fig. S12. CV curves recorded from the (a) Pd@Ir cube/C, (b) Pd@Ir oct/C and (c) Pd@Ir TOH/C and corresponding Pd seed counterparts. 


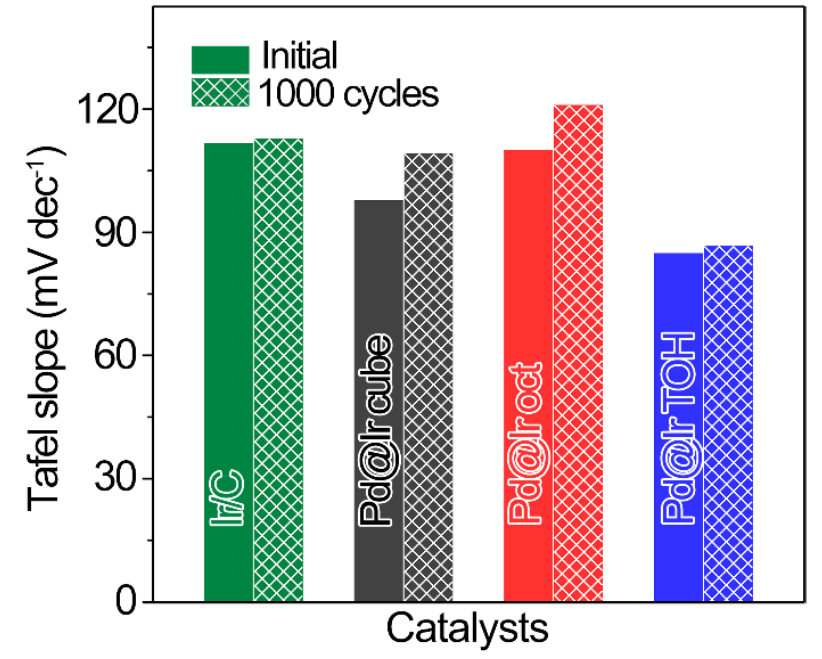

Fig. S13. Tafel slopes of Ir/C, Pd@Ir cube/C, Pd@Ir oct/C and Pd@Ir TOH/C before and after 1000 cycles. 


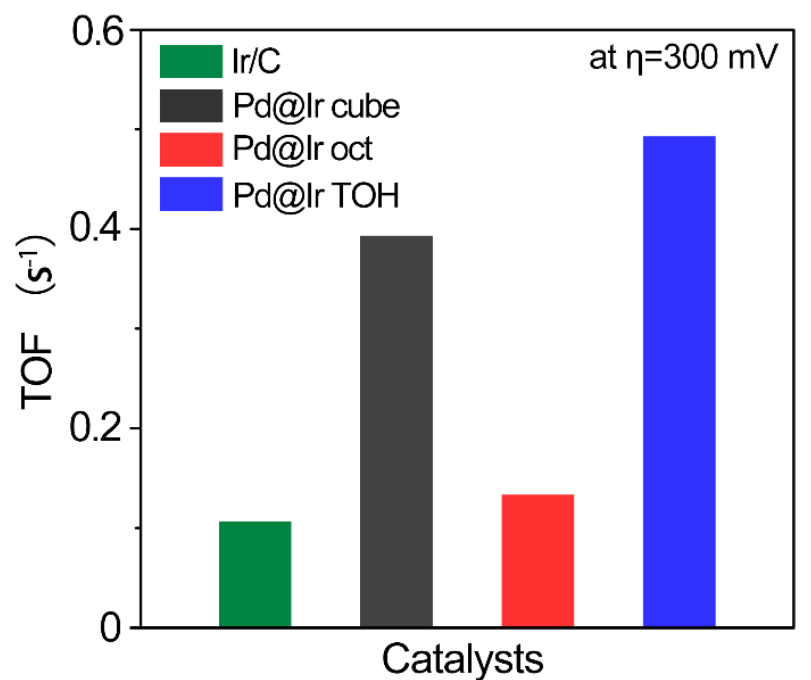

Fig. S14. Turnover frequency (TOF) of the of Ir/C, Pd@Ir cube/C, Pd@Ir oct/C and Pd@Ir TOH/C at $\eta=300 \mathrm{mV}$. 
a)

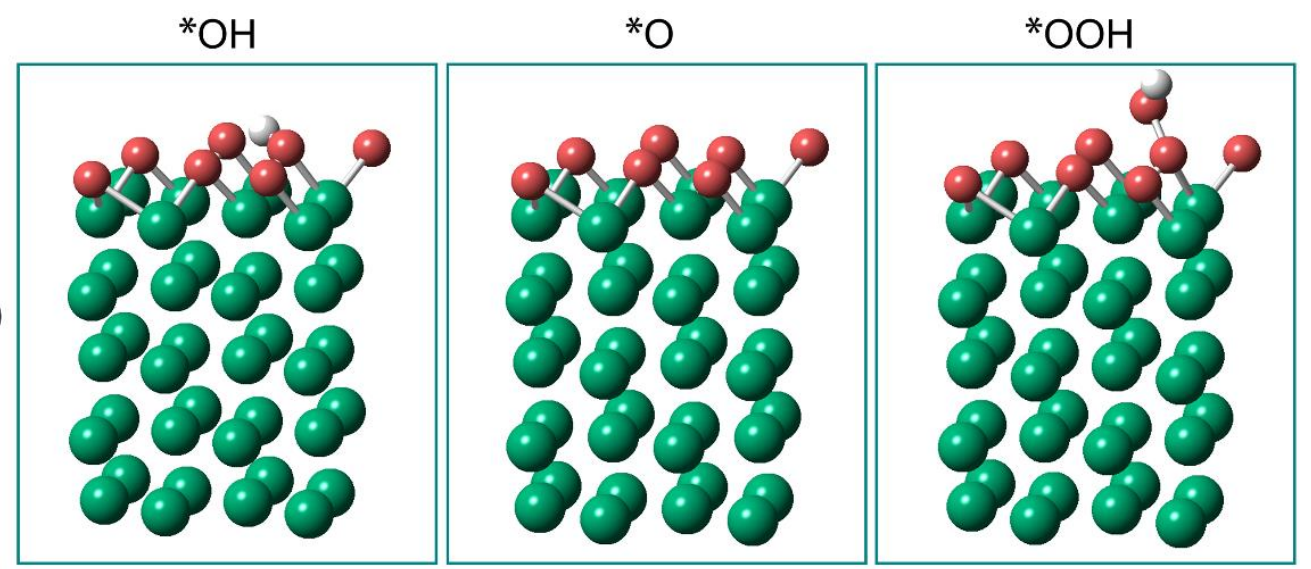

b)

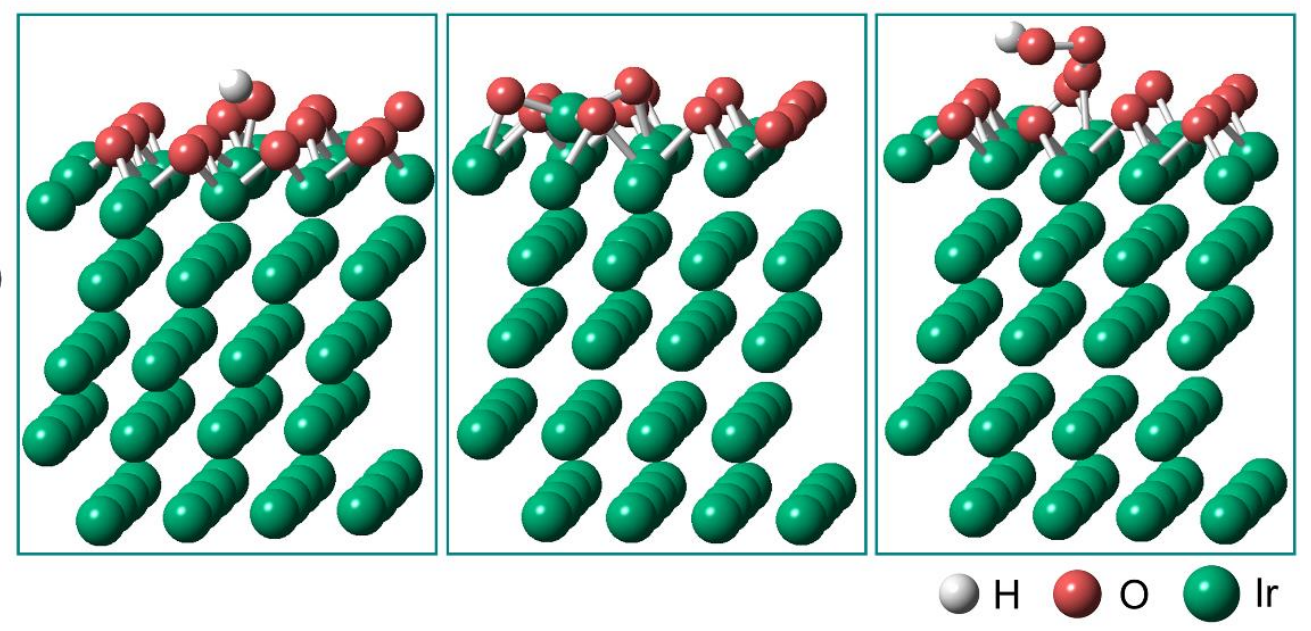

Fig. S15. The chemisorption models of oxygen intermediates on (a) $\operatorname{Ir}(100)$ and (b) $\operatorname{Ir}(111)$ in acidic condition. 


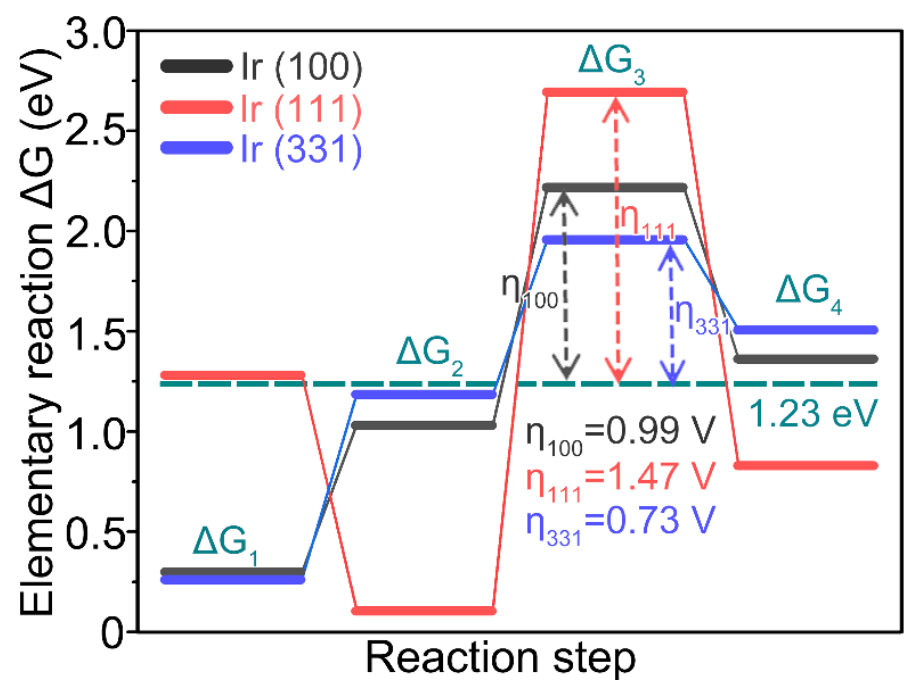

Fig. S16. Calculated adsorption free energy change of each step for OER of $\operatorname{Ir}(100), \operatorname{Ir}(111)$ and $\operatorname{Ir}$ (331). 


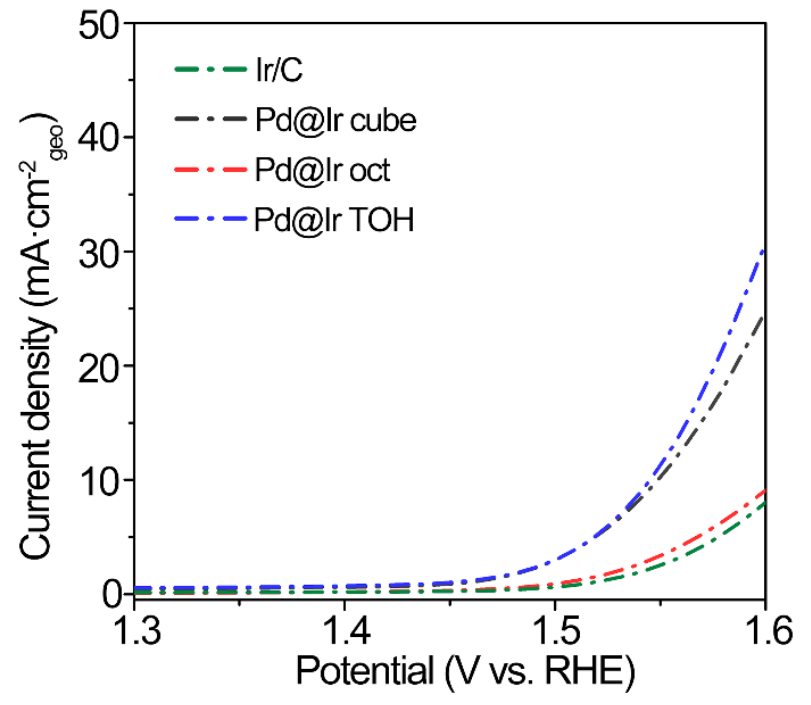

Fig. S17. LSV curves of Ir/C, Pd@Ir cube/C, Pd@Ir oct/C and Pd@Ir TOH/C catalysts after 1000 cycles of durability test. 


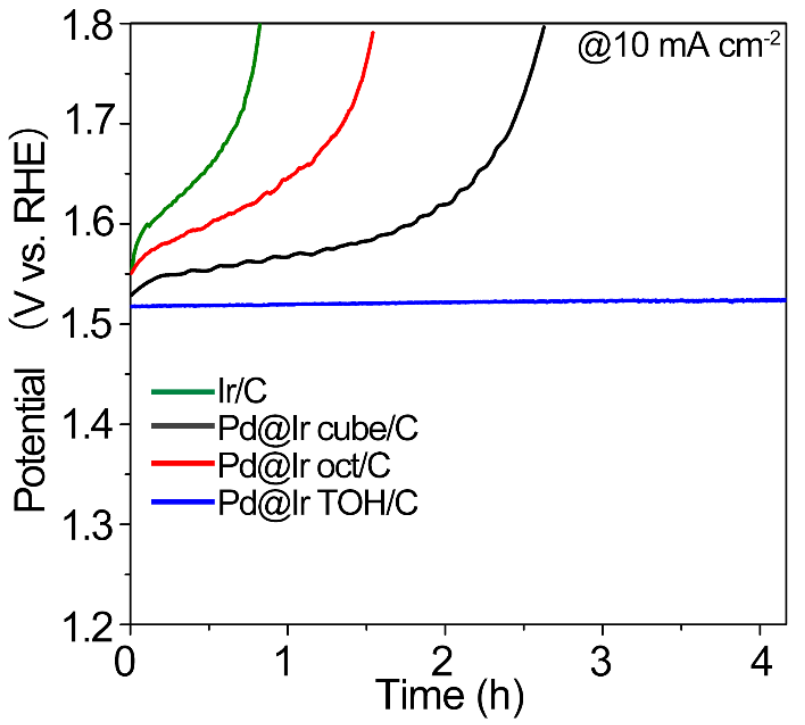

Fig. S18. OER chronopotentiometry measurements of Ir/C, Pd@Ir cube/C, Pd@Ir oct/C and Pd@Ir $\mathrm{TOH} / \mathrm{C}$ at $10 \mathrm{~mA} \mathrm{~cm}$ geo $^{-2}$ for $4 \mathrm{~h}$ in $\mathrm{O}_{2}$-saturated $0.1 \mathrm{~m} \mathrm{HClO}_{4}$ solution. 


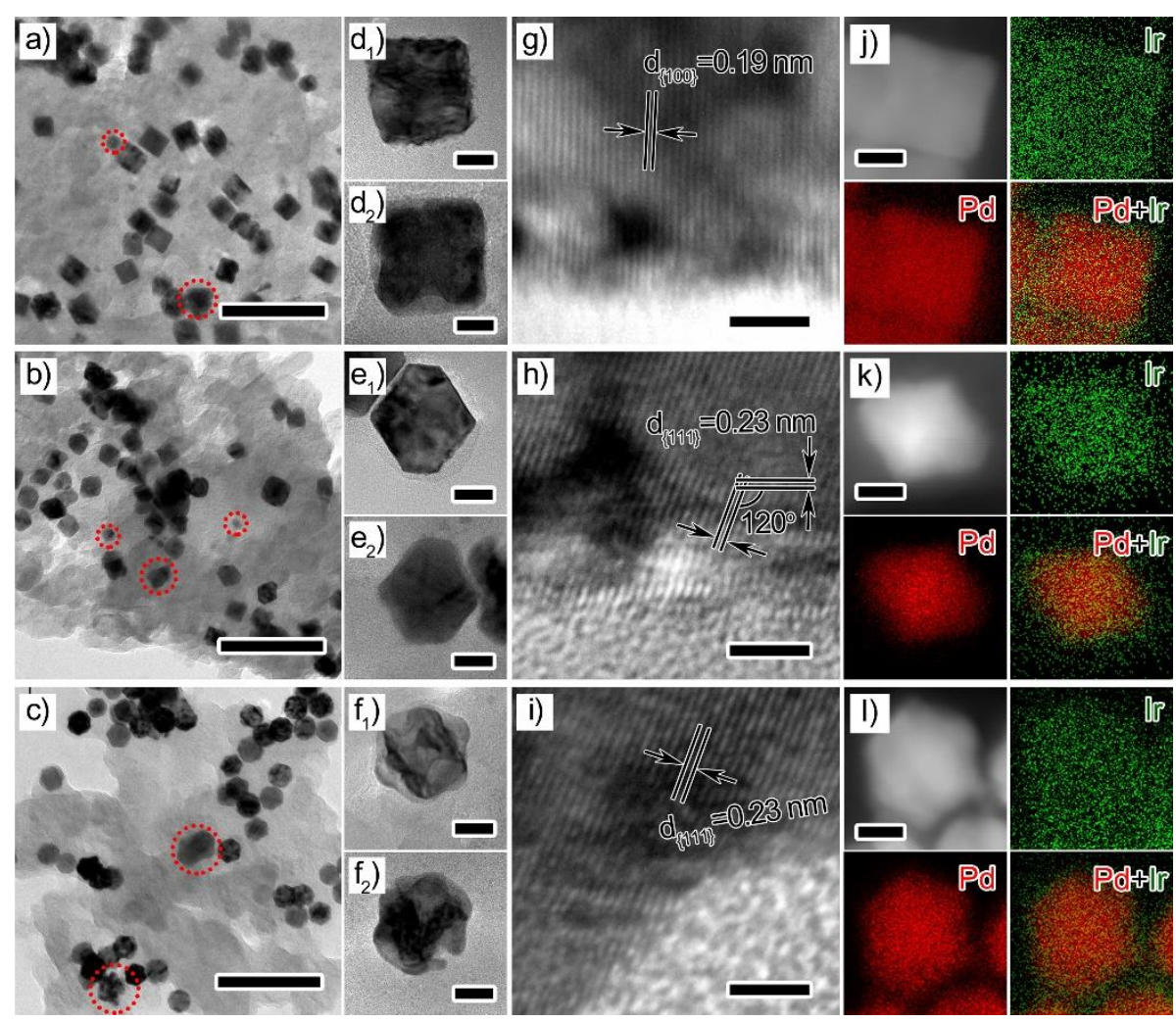

Fig. S19. (a-c) TEM images of Pd@Ir cube, Pd@Ir oct and Pd@Ir TOH after 1000 cycles of test, respectively (scale bar: $200 \mathrm{~nm}$ ). (d-f) The typical TEM images in high magnification of structuredeteriorated Pd@Ir cube, Pd@Ir oct and Pd@Ir TOH after 1000 cycles of test, respectively (scale bar: 10 nm). (g-i) HRTEM images of structure-deteriorated Pd@Ir cube, Pd@Ir oct and Pd@Ir TOH after 1000 cycles of test, respectively (scale bar: $2 \mathrm{~nm}$ ). (j-1) HAADF-STEM images of structuredeteriorated Pd@Ir cube, Pd@Ir oct and Pd@Ir TOH after 1000 cycles of test and corresponding energy-dispersive X-ray spectroscopy mappings of Pd and $\operatorname{Ir}$ (scale bar: $20 \mathrm{~nm}$ ). 


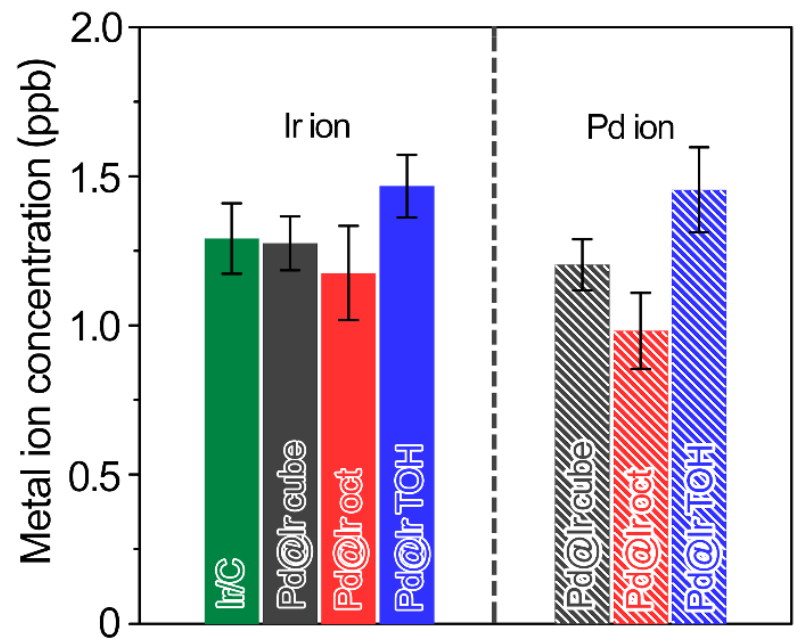

Fig. S20. The Ir and Pd ion concentrations dissolved in the electrolyte after 1000 cycles of durability test (1.2-1.6 V, vs RHE) measured by ICP-MS analysis for all the samples. Error bars are standard error values of at least three tests. 

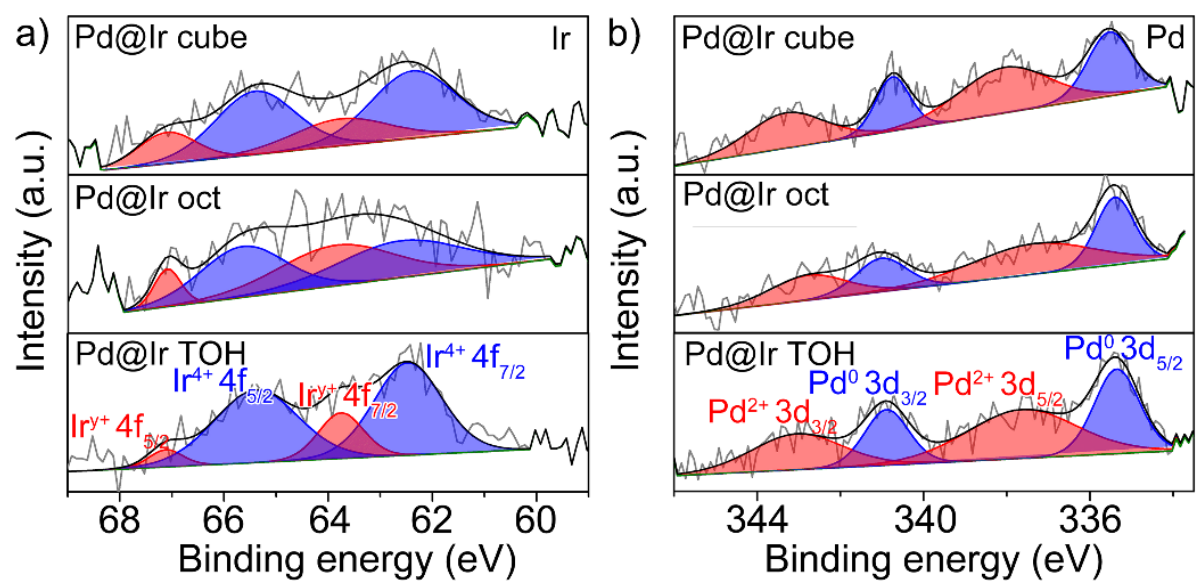

Fig. S21. (a) Ir 4f and (b) Pd 3d high resolution spectra in Pd@Ir cube, Pd@Ir oct and Pd@Ir TOH after 1000 cycles. 


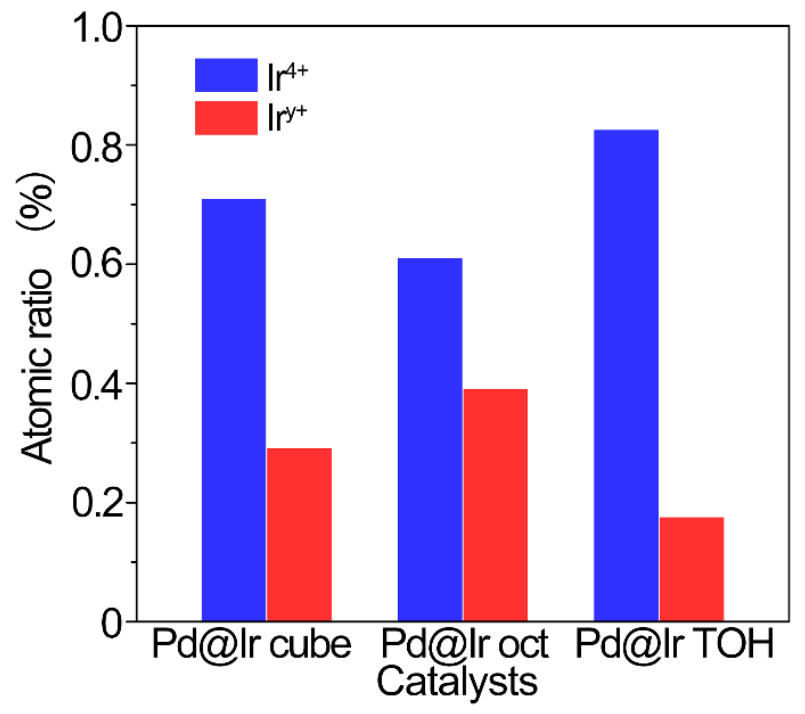

Fig. S22. Atomic ratios of $\operatorname{Ir}^{0}$ and $\operatorname{Ir}^{4+}$ in Ir shell for Pd@Ir core-shell electrocatalysts after 1000 cycles. 
Table S1. The relationship between projection angles and facet Miller indices for trioctahedron.

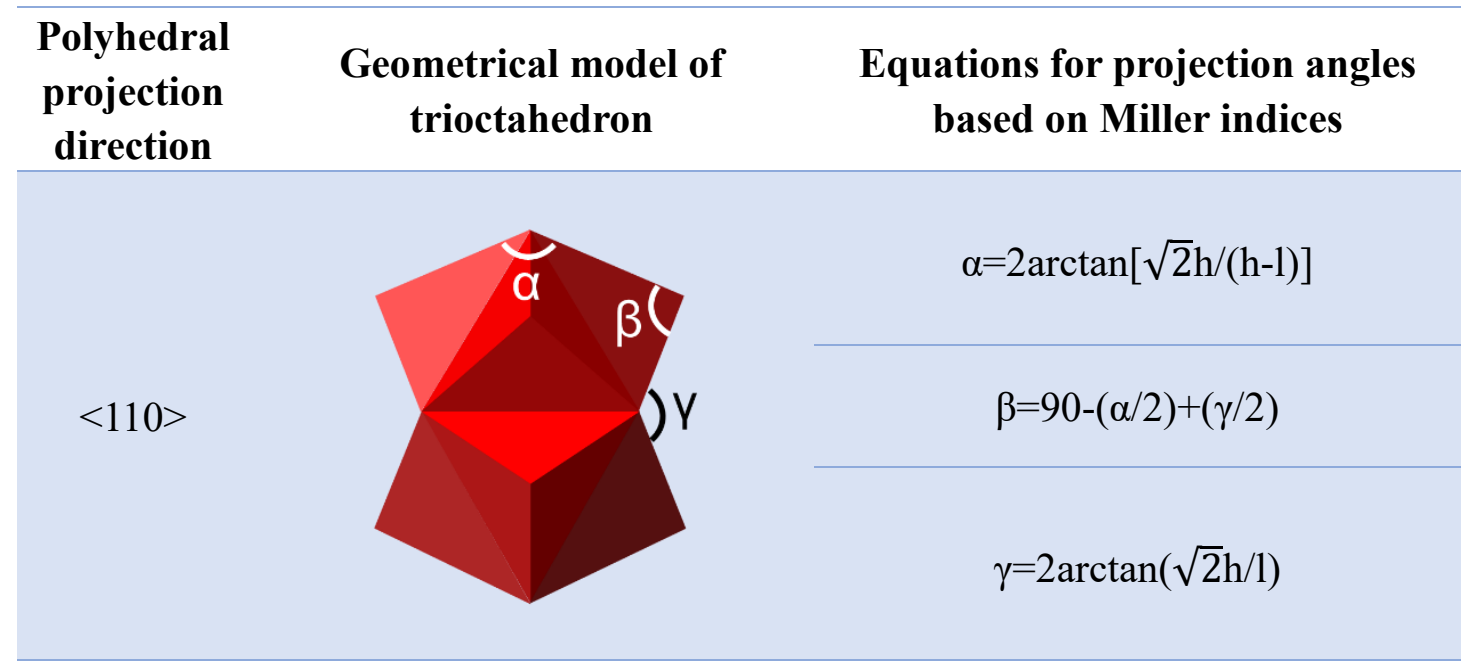

Relationship between calculated projection angle and Miller index

\begin{tabular}{cccc}
\hline Miller index $\{\mathbf{h h l}\}$ & $\boldsymbol{\alpha}$ & $\boldsymbol{\beta}$ & $\boldsymbol{\gamma}$ \\
\hline$\{\mathbf{2 2 1}\}$ & $141^{\circ}$ & $90^{\circ}$ & $141^{\circ}$ \\
\hline$\{\mathbf{3 3 1}\}$ & $129.5^{\circ}$ & $102^{\circ}$ & $153.5^{\circ}$ \\
\hline$\{\mathbf{4 4 1}\}$ & $124^{\circ}$ & $108^{\circ}$ & $160^{\circ}$ \\
\hline$\{\mathbf{5 5 2}\}$ & $134^{\circ}$ & $97^{\circ}$ & $148.5^{\circ}$ \\
\hline
\end{tabular}


Table S2. Concentration and weight percentage of Pd and Ir in Pd@Ir catalysts with various shapes.

\begin{tabular}{|ccccc|}
\hline Samples & $\begin{array}{c}\text { Concentration } \\
\text { of } \mathbf{I r}(\boldsymbol{\mu g} / \boldsymbol{\mu L})\end{array}$ & $\begin{array}{c}\text { Concentration } \\
\text { of } \mathbf{P d}(\boldsymbol{\mu g} / \boldsymbol{\mu L})\end{array}$ & wt\% of Ir & wt\% of Pd \\
\hline Ir & 0.0728 & 0 & 100 & 0 \\
\hline Pd@Ir cube & 0.0208 & 0.58 & 3.46 & 96.54 \\
\hline Pd@Ir oct & 0.0253 & 0.658 & 3.70 & 96.30 \\
\hline Pd@Ir TOH & 0.0184 & 0.585 & 3.05 & 96.95 \\
\hline
\end{tabular}


Table S3. Weight percentage of Ir and average number of Ir atomic layers calculated from the ICP-MS in the Pd@Ir catalysts with various shapes.

\begin{tabular}{cccc}
\hline Samples & $\begin{array}{c}\text { wt\% of Ir } \\
\text { calculated from } \\
\text { ICP-MS }\end{array}$ & $\begin{array}{c}\text { wt\% of Ir } \\
\text { calculated from } \\
\text { the value of } \mathbf{n}\end{array}$ & $\begin{array}{c}\text { Average number of } \\
\text { Ir atomic layers }\end{array}$ \\
\hline Pd@Ir cube & 3.46 & $4.60(\mathrm{n}=1)$ & 0.8 \\
\hline Pd@Ir oct & 3.70 & $4.82(\mathrm{n}=1)$ & 0.8 \\
\hline Pd@Ir TOH & 3.05 & $3.04(\mathrm{n}=1)$ & 1.0 \\
\hline
\end{tabular}


Table S4. Atomic ratios of $\operatorname{Ir}^{0}$ and $\mathrm{Ir}^{4+}$ in Ir shell for Pd@Ir core-shell electrocatalyst.

\begin{tabular}{|c|c|c|c|c|c|c|}
\hline Samples & $\begin{array}{l}\operatorname{atm} \% \text { of } \\
\operatorname{Ir}^{(0)} 4 f_{7 / 2}\end{array}$ & $\begin{array}{l}\operatorname{atm} \% \text { of } \\
\operatorname{Ir}^{(0)} 4 f_{5 / 2}\end{array}$ & $\begin{array}{l}\text { atm\% } \\
\text { of } \operatorname{Ir}^{(0)}\end{array}$ & $\begin{array}{l}\operatorname{atm} \% \text { of } \\
\operatorname{Ir}^{(I V)} 4 f_{7 / 2}\end{array}$ & $\begin{array}{c}\operatorname{atm} \% \text { of } \\
\operatorname{Ir}^{(I V)} 4 f_{5 / 2}\end{array}$ & $\begin{array}{l}\operatorname{atm} \% \\
\text { of } \operatorname{Ir}^{(I V)}\end{array}$ \\
\hline $\begin{array}{c}\text { Pd@Ir } \\
\text { cube }\end{array}$ & 28.80 & 28.53 & 57.33 & 22.66 & 20.01 & 42.67 \\
\hline $\begin{array}{c}\text { Pd@Ir } \\
\text { oct }\end{array}$ & 30.78 & 35.31 & 66.09 & 17.69 & 16.22 & 33.91 \\
\hline $\begin{array}{c}\text { Pd@Ir } \\
\text { TOH }\end{array}$ & 24.00 & 21.33 & 45.33 & 33.15 & 21.52 & 54.67 \\
\hline
\end{tabular}


Table S5. ZPE correction and entropy correction on Gibbs free energy for different facets of Ir.

\begin{tabular}{ccc} 
Object & ZPE & TS \\
\hline H2O & 0.58 & 0.67 \\
\hline H2 & 0.27 & 0.41 \\
\hline HO*@Ir (100) & 0.38 & - \\
\hline O*@Ir (100) & 0.08 & - \\
\hline HOO*@Ir (100) & 0.44 & - \\
\hline HO*@Ir (111) & 0.36 & - \\
\hline O*@Ir (111) & 0.08 & - \\
\hline HOO*@Ir (111) & 0.45 & - \\
\hline HO*@Ir (331) & 0.37 & - \\
\hline O*@Ir (331) & 0.06 & - \\
\hline HOO*@Ir (331) & 0.43 & gas phase molecules entropy corrections are from \\
\hline ZPE corrections are calculated and the \\
experimental values.
\end{tabular}


Table S6. Calculated adsorption free energy of different oxygen-based intermediate species for OER at $U=0$ and overpotential ( $\eta$ ) of $\operatorname{Ir}(100), \operatorname{Ir}(111)$ and $\operatorname{Ir}(331)$.

\begin{tabular}{|c|c|c|c|c|c|}
\hline Catalysts & $\Delta G_{\text {H2O }}(\mathrm{eV})$ & $\Delta \mathrm{G} * \mathrm{OH}(\mathrm{eV})$ & $\Delta G * 0(e V)$ & $\Delta \mathrm{G} * \mathrm{OOH}(\mathrm{eV})$ & $\Delta G_{02}(e V)$ \\
\hline $\operatorname{Ir}(100)$ & 0 & 0.30 & 1.34 & 3.59 & 4.92 \\
\hline Ir (111) & 0 & 1.29 & 1.40 & 4.11 & 4.92 \\
\hline Ir (331) & 0 & 0.26 & 1.46 & 3.40 & 4.92 \\
\hline
\end{tabular}


Table S7. Calculated adsorption free energy change of each step for OER at $\mathrm{U}=0$ and overpotential ( $\eta)$ of $\operatorname{Ir}(100), \operatorname{Ir}(111)$ and $\operatorname{Ir}(331)$.

\begin{tabular}{rcccccc} 
Catalysts & $\boldsymbol{\Delta} \mathbf{G}_{\mathbf{1}}(\mathbf{e V})$ & $\boldsymbol{\Delta} \mathbf{G}_{\mathbf{2}}(\mathbf{e V})$ & $\boldsymbol{\Delta} \mathbf{G}_{\mathbf{3}}(\mathbf{e V})$ & $\boldsymbol{\Delta} \mathbf{G}_{\mathbf{4}}(\mathbf{e V})$ & $\boldsymbol{\eta}(\mathbf{e V})$ \\
\hline $\mathbf{I r}(\mathbf{1 0 0})$ & 0.30 & 1.03 & 2.22 & 1.37 & 0.99 \\
\hline $\mathbf{I r}(\mathbf{1 1 1})$ & 1.23 & 0.11 & 2.70 & 0.83 & 1.47 \\
\hline $\mathbf{I r}(\mathbf{3 3 1})$ & 0.26 & 1.19 & 1.96 & 1.51 & 0.73 \\
\hline
\end{tabular}


Table S8. Ir and Pd ion concentrations in the electrolyte after the 1000 cycles $^{\mathrm{a}}$

\begin{tabular}{|c|c|c|c|c|}
\hline Samples & $\mathrm{Ir} / \mathrm{C}$ & $\begin{array}{l}\text { Pd@Ir } \\
\text { cube/C }\end{array}$ & $\begin{array}{c}\text { Pd@Ir } \\
\text { oct/C }\end{array}$ & $\begin{array}{l}\text { Pd@Ir } \\
\text { TOH/C }\end{array}$ \\
\hline $\begin{array}{c}\text { Ir ion concentration } \\
(\mathbf{p p b})\end{array}$ & $1.29 \pm 0.12$ & $1.28 \pm 0.09$ & $1.18 \pm 0.16$ & $1.47 \pm 0.11$ \\
\hline $\begin{array}{c}\text { Pd ion } \\
\text { concentration (ppb) }\end{array}$ & - & $1.20 \pm 0.09$ & $0.98 \pm 0.13$ & $1.45 \pm 0.14$ \\
\hline
\end{tabular}


Table S9. Atomic ratios of $\mathrm{Ir}^{4+}$ and $\mathrm{Ir}^{5+}$ in Ir shell for Pd@Ir core-shell electrocatalysts after 1000 cycles.

\begin{tabular}{|c|c|c|c|c|c|c|}
\hline Samples & $\begin{array}{l}\text { atm\% of } \\
\operatorname{Ir}^{4+} 4 f_{7 / 2}\end{array}$ & $\begin{array}{l}\operatorname{atm} \% \text { of } \\
\mathrm{Ir}^{4+} 4 f \mathbf{5 / 2}\end{array}$ & $\begin{array}{l}\text { atm } \% \\
\text { of } \mathrm{Ir}^{4+}\end{array}$ & $\begin{array}{c}\operatorname{atm} \% \text { of } \\
\operatorname{Ir}^{y+} 4 f_{7 / 2}\end{array}$ & $\begin{array}{l}\text { atm\% of } \\
\operatorname{Ir}^{y+} 4 f f_{5 / 2}\end{array}$ & $\begin{array}{l}\operatorname{atm} \% \\
\text { of } \operatorname{Ir}^{y^{+}}\end{array}$ \\
\hline $\begin{array}{c}\text { Pd@Ir } \\
\text { cube }\end{array}$ & 37.57 & 33.35 & 70.92 & 11.98 & 17.09 & 29.07 \\
\hline $\begin{array}{c}\text { Pd@Ir } \\
\text { oct }\end{array}$ & 29.64 & 31.39 & 61.03 & 6.93 & 32.04 & 38.97 \\
\hline $\begin{array}{c}\text { Pd@Ir } \\
\text { TOH }\end{array}$ & 41.78 & 40.71 & 82.49 & 3.87 & 13.65 & 17.52 \\
\hline
\end{tabular}

